\title{
Erratum to: Seeking to understand: using generic qualitative research to explore access to medicines and pharmacy services among resettled refugees
}

\author{
Kim Bellamy ${ }^{1} \cdot$ Remo Ostini $^{2} \cdot$ Nataly Martini $^{3} \cdot$ Therese Kairuz $^{4}$
}

Published online: 9 March 2016

(C) Springer International Publishing 2016

\section{Erratum to: Int J Clin Pharm DOI 10.1007/s11096-016-0261-1}

In the original publication of this article, the paragraph under the sub-heading 'Methodological approach' has been published incorrectly. The correct paragraph is provided in this erratum.

If the focus of a topic is outward, i.e. on the contents of opinion and on actual world experiences and happenings rather than on participants' 'inner feelings', Percy [7] recommends that one should consider a generic qualitative approach. This approach may also be selected when: (1) the research problem and question require a mixed-methods methodology; (2) traditional qualitative approaches are inappropriate because the focus of the research, the content of the information desired, or the kind of data to be obtained does not fit these approaches; or (3) the researcher has a body of pre-knowledge about a topic that he or she wants to be able to describe more fully from the participants' perspective [7].
The online version of the original article can be found under doi:10.1007/s11096-016-0261-1.

Kim Bellamy

k.bellamy@uq.edu.au

1 School of Pharmacy, The University of Queensland, Brisbane, Australia

2 Rural Clinical School Research Centre, School of Medicine, The University of Queensland, Ipswich, Australia

3 School of Pharmacy, University of Auckland, Auckland, New Zealand

4 Pharmacy, College of Medicine and Dentistry, James Cook University, Townsville, Australia 